\title{
Flame Retardancy and Mechanical Properties of Chitosan and DOPO with Different Mass Ratios in Epoxy Resin
}

\section{Junjie Wang}

Wuhan Institute of Technology

\section{Xinyu Wang}

Wuhan Institute of Technology

Chenyu Zhou

Wuhan Institute of Technology

Zhiquan Pan

Wuhan Institute of Technology

Hong Zhou ( $\nabla$ hzhouh@126.com )

Wuhan Institute of Technology https://orcid.org/0000-0003-2409-784X

\section{Research Article}

Keywords: Epoxy resin, Chitosan, DOPO, Flame retardancy, Different mass ratios

Posted Date: December 8th, 2021

DOI: https://doi.org/10.21203/rs.3.rs-1095633/v1

License: (9) This work is licensed under a Creative Commons Attribution 4.0 International License. Read Full License 


\section{Abstract}

This work focused on the effects of chitosan (CS) and 9,10-dihydro-9-oxo-10-phosphaphenanthrene-10oxide (DOPO) on the flammable propertied of epoxy resin matrix. The EP composites were fabricated by direct mixing method through a general curing method. The influence of CS, DOPO and CS / DOPO on the resin was investigated through cone calorimetry tests (CC), UL-94 vertical burning, limiting oxygen index (LOI), thermal gravimetric analyzer (TGA), differential scanning calorimeter (DSC) and thermogravimetric analyzer-Fourier infrared combined system (TG-FTIR). The char residues of modified EPs after CC tests were investigated by FTIR, EDX and XPS. Under the 10\% addition of CS / DOPO in EP, with the mass ratio of CS and DOPO of $1: 1,1: 2,1: 3,2: 1$ and $3: 1$, the flame retardancy properties of EPs all increased, but only if EP/10\% CS1/DOPO2 and EP/10\% CS2/DOPO1 achieved a V-0 rating and their values of LOI were $33.7 \%$ and $32.5 \%$, respectively. Compared with EP, the peak heat release rate, peak smoke produce rate and total heat release of EP/10\% CS1/DOPO2 and EP/10\% CS2/DOPO1 decreased, especially, total smoke release decreased by $61.9 \%$ and $71.0 \%$, the char residuals amount increased by $84.3 \%$ and $41.6 \%$, and the average $\mathrm{CO}_{2}$ yield decreased by $55.4 \%$ and $55.0 \%$, respectively. It is worth nothing that the mechanical properties increased, especially the flexural strength increased by $36.0 \%$ and $38.4 \%$, respectively. The results indicated that DOPO and CS had important synergistic effects for simultaneous increase both the flame retardancy and mechanical properties of EP composites.

\section{Introduction}

Epoxy resin is a kind of polymer material that is widely used and has obvious merits and demerits (Wang et al. 2020; Kandola et al. 2010; Ai et al. 2020). Applications in more fields were limited due to its significant flammable defects (Wang et al. 2006). At present, the fire resistancy of epoxy resins has been extensively studied and the direct addition of flame retardants is considered to be the most direct, efficient and economical usage mode (Tang et al. 2019; Netkueakul et al. 2020). However, the addition of some flame retardants will generally reduce the mechanical properties of epoxy resin (Zou et al. 2020). The DOPO derivatives were widely used as phosphorous flame retardants in EP. Xie et al. synthesized a flame retardant named MBF-DOPO, when 4\% MBF-DOPO was added, the samples obtained the V-0 rating in UL-94 test, and the limiting oxygen index (LOI) reached to $32.9 \%$. Compared to EP, the peak heat release rate and total smoke production values were decreased by $29.3 \%$ and $33.6 \%$, respectively (Xie et al. 2020). A flame retardant TAD was synthesized by Tang et al., when the mass fraction of TAD reached 12 wt.\%, the samples acquired the highest LOI value of $33.5 \%$ and passed the UL94 V-0 rating (Tang et al. 2016). However, the addition of all above mentioned flame retardants in EP resulted in the decrease of the mechanical properties of EP composites.

Intumescent flame retardant (IFR) is a type of flame retardant composites, mainly composed of nitrogen and phosphorus, which is foamed and expanded when heated. It is halogen-free and does not use antimony oxide as a synergist (Lai et al. 2011). Hereby, it is a kind of environmentally flame retardant with high efficiency and low toxicity (Chen et al. 2015; Li et al. 2009). The flame retardancy of IFR mainly depends on the density, quality and strength of the carbon layer, and the matching between the 
components is essential (Liu et al. 2015; Huang et al. 2020). Previously, PER (pentaerythritol)-based carbon source had been paid much attention by researchers, which was basically petroleum derivatives (Xu et al. 2018). The main mechanism was that the hydroxyl group in its molecular structure could crosslink with the inorganic acid produced by the decomposition of acid source during combustion (Xie 2013).

Chitosan is a kind of natural biomass with abundant content in nature, and the molecular structure contains both hydroxyl and amine groups (Kim et al. 2017). It is a kind of alkaline polysaccharide with rich carbon source (Hoqani et al. 2020). Not only that, but nonflammable gases can be supplied during combustion. However, when single chitosan was used as flame retardant, its poor thermal stability and low charring efficiency at high temperature limited its application in the field where flame retardancy is required. In order to increase the carbonization efficiency of chitosan, the main research direction was to carry out chemical modification, using the active amine and hydroxyl carried by chitosan itself, so as to increase the thermal stability of chitosan and improve the carbonization efficiency (Chen et al. 2020; Pan et al. 2015; Goda et al. 2021).

In order to improve efficiency and reduce energy consumption and cost, in this paper, CS and DOPO were directly compounded in a certain mass ratio, and the halogen-free flame retardancy EP composites were prepared by melt blending. The influence of the addition of CS / DOPO flame retardant system on the flame retardancy of epoxy resin was analyzed, and on the basis, the influence mechanism of different mass ratios of CS and DOPO on the flame retardancy properties of epoxy resin composites was also investigated, which provided basic experimental data and theoretical support for the wide application of chitosan in polymers. When the addition amount of CS / DOPO was $10 \%$ and the mass ratio of CS to DOPO was $1: 2$ and 2:1, the LOI value of EP/10\% CS1/DOPO2 and EP/10\% CS2/DOPO2 increased to $33.7 \%$ and $32.5 \%$, respectively, and passed UL-94 V-0 rating both.

Meanwhile, the thermal properties of modified EPs were tested by thermogravimetric analyzer (TGA) and differential scanning calorimeter (DSC). The flame retardancy properties of modified EPs were analyzed by LOI (limiting oxygen index), UL-94 vertical burning test and cone calorimeter (CC). The morphology and composition of the char residual layer of modified thermosetting polymer were studied by SEM (Scanning Electron Microscope), Raman spectra and EDX (Energy Dispersive Spectxrmleter), and the flame retardancy mechanism was analyzed.

\section{Experimental}

\subsection{Raw materials}

Epoxy resin (DGEBA, E-44, diglycidyl ether of bisphenol A, expoxy equiv $210-230 \mathrm{~g} / \mathrm{mol}$, hydrolysable chlorine $\leq 0.5 \%$, inorganic chlorine $\leq 50 \mathrm{mg} / \mathrm{kg}$ and softening point $14-23^{\circ} \mathrm{C}$ ) was provided by Nantong Xingchen Synthetic Materials Co., LTD, Huangshi, China. Chitosan, DOPO and Diamino diphenylmethane (DDM), were purchased from Sinopharm Chemical Reagent Co., Ltd, Shanghai, China. 


\subsection{Preparation of modified EPs}

In order to investigate the flame retardancy of CS / DOPO in EP, CS and DOPO were added to EP at different total additions and mass ratios. The preparation of modified EPs can be implemented according to Fig. 1 as followings: Firstly, CS, DOPO and DGEBA were mixed uniformly in a two-necked flask at 100 ${ }^{\circ} \mathrm{C}$ under vacuum for about $30 \mathrm{~min}$, and stirred vigorously to obtain a homogeneous liquid. Then, the temperature dropped to $95^{\circ} \mathrm{C}$, DDM was added, and stirred under vacuum condition. Finally, the curing process was carried out on the plate vulcanization machine. The mixture was poured into the prepared mold and put into the plate vulcanization machine. The whole curing process included two stages: curing at $100^{\circ} \mathrm{C}$ for two hours and at $150^{\circ} \mathrm{C}$ for another two hours. The various modified EP samples labeled on the basis of their compositions, were listed in Table 1. For example, the label EP/10\% CS1/DOPO2 indicated that the total amount of CS and DOPO in the samples was $10 \%$, and the mass ratio of CS and DOPO was $1: 2$.

Table 1

Formulations of EP and EP/CS/DOPO samples

\begin{tabular}{|c|c|c|c|c|c|c|}
\hline Samples & $\mathrm{EP}(\mathrm{g})$ & $\operatorname{DDM}(\mathrm{g})$ & $\begin{array}{l}\text { CS/DOPO } \\
\text { (wt/wt) }\end{array}$ & DOPO (g) & $\begin{array}{l}\text { CS } \\
(g)\end{array}$ & $\begin{array}{l}P \\
w t \%\end{array}$ \\
\hline EP & 25 & 6.5 & - & 0 & 0 & 0 \\
\hline $\mathrm{EP} / 8 \% \mathrm{CS}$ & 25 & 6.5 & - & 0 & 2.74 & 0 \\
\hline EP/8\% DOPO & 25 & 6.5 & - & 2.74 & 0 & 0.54 \\
\hline $\mathrm{EP} / 8 \% \mathrm{CS} 1 / \mathrm{DOP} 01$ & 25 & 6.5 & $1: 1$ & 1.37 & 1.37 & 0.27 \\
\hline EP/8\% CS1/DOPO2 & 25 & 6.5 & $1: 2$ & 0.91 & 1.83 & 0.36 \\
\hline EP/8\% CS2/DOP01 & 25 & 6.5 & $2: 1$ & 1.83 & 0.91 & 0.18 \\
\hline EP/8\% CS1/DOPO3 & 25 & 6.5 & $1: 3$ & 0.69 & 2.05 & 0.41 \\
\hline EP/8\% CS3/DOPO1 & 25 & 6.5 & $3: 1$ & 2.05 & 0.69 & 0.14 \\
\hline $\mathrm{EP} / 10 \% \mathrm{CS}$ & 25 & 6.5 & - & 3.5 & 0 & 0 \\
\hline EP/10\% DOPO & 25 & 6.5 & - & 0 & 3.5 & 0.68 \\
\hline $\mathrm{EP} / 10 \% \mathrm{CS} 1 / \mathrm{DOPO} 1$ & 25 & 6.5 & $1: 1$ & 1.75 & 1.75 & 0.34 \\
\hline $\mathrm{EP} / 10 \% \mathrm{CS} 1 / \mathrm{DOPO} 2$ & 25 & 6.5 & $1: 2$ & 1.17 & 2.33 & 0.46 \\
\hline $\mathrm{EP} / 10 \% \mathrm{CS} 2 / \mathrm{DOPO} 1$ & 25 & 6.5 & $2: 1$ & 2.33 & 1.17 & 0.23 \\
\hline EP/10\% CS1/DOPO3 & 25 & 6.5 & $1: 3$ & 0.87 & 2.63 & 0.51 \\
\hline EP/10\% CS3/DOPO1 & 25 & 6.5 & $3: 1$ & 2.63 & 0.87 & 0.22 \\
\hline
\end{tabular}

\subsection{Methods}


Differential scanning calorimeter (DSC) spectra were obtained by a TA Q10 DSC instrument to investigate the glass transition temperature $\left(T_{g}\right)$ of the modified EPs. The $T_{g}$ of epoxy thermosets samples were determined by heating from $40{ }^{\circ} \mathrm{C}$ to $200{ }^{\circ} \mathrm{C}$ at a heating rate of $10{ }^{\circ} \mathrm{C} / \mathrm{min}$.

Thermogravimetric analysis was recorded with a thermal analyzer (TGA, TGA/DSC3+, Switzerland). The test was conducted by heating from $30^{\circ} \mathrm{C}$ to $790^{\circ} \mathrm{C}$ under nitrogen. The heating rate was $10{ }^{\circ} \mathrm{C} / \mathrm{min}$.

The LOI value was obtained on an HC-2C oxygen index instrument with sheet dimensions of $130 \times 6.5 \times$ $3.2 \mathrm{~mm}^{3}$. The UL-94 rating was measured with sheet dimensions of $130 \times 13 \times 3.2 \mathrm{~mm}^{3}$. The cone calorimeter (CC) tests were conducted following the standard ISO 5660 with sheet dimensions of $100 \times$ $100 \times 3.2 \mathrm{~mm}^{3}$ under an external heat flux of $35 \mathrm{~kW} / \mathrm{m}^{2}$.

Scanning Electron Microscopy (SEM) and Energy Dispersive X-ray spectroscopy (EDX) were used to determine the sample morphologies and elemental distribution throughout the sample granules, respectively. The JEOL model JSM-5900LV SEM was applied to determine morphologies of char residuals. EDX was performed using Link Isis series 300 program to determine various elements distribution as a density mapping of the specified element.

FTIR spectra of the char residues for EPs were recorded on a Thermo Nicolet 5700 FTIR spectrophotometer using the $\mathrm{KBr}$ disk in a wavenumber range of $4000-400 \mathrm{~cm}^{-1}$.

X-ray photoelectron spectra (ESCALAB 250xi, US) of the char residues after cone calorimeter tests were recorded on using AlKa radiation $(1486.6 \mathrm{eV})$ in ultrahigh vacuum conditions.

Raman spectroscopy (LabRAMHR800) was conducted to characterize the types of the carbon under 514 $\mathrm{nm}$ helium-neon laser line with wavelength range of $200-4000 \mathrm{~cm}^{-1}$.

TG-FTIR was used to analyze the FTIR spectra of the gas components from the TGA, and the real time FTIR analysis of the pyrolysis gases was conducted on a thermogravimeter (TG219 F3, Netzsch Instruments, Germany) and a Fourier transforminfrared spectrometer (Nicolet IS50, Thermo Fisher Scientific, USA.), the transfer line of gases from TGA to FTIR was heated at $280{ }^{\circ} \mathrm{C}$. The investigation was carried out at temperatures ranging from $40{ }^{\circ} \mathrm{C}$ to $800{ }^{\circ} \mathrm{C}$.

The flexural and tensile tests of the samples were recorded on CMT4104 universal testing machine (SANS) with a dumbbell sheet dimensions of $75 \times 4 \times 2 \mathrm{~mm}^{3}$ and a rectangle of $80 \times 10 \times 4 \mathrm{~mm}^{3}$, separately, according to the standard of GB/T 9341-2008 and GB/T 1040.2-2006. Three samples were measured each time, and the average value was taken.

\section{Results And Discussion}

\subsection{Thermal stability}


The glass transition temperature $\left(T_{g}\right)$ of modified EPs was characterized by DSC tests. In Fig. 2, EP exhibited a high $\mathrm{T}_{\mathrm{g}}$ value of $154.7^{\circ} \mathrm{C}$. With CS / DOPO supplementation, the $\mathrm{T}_{\mathrm{g}}$ values of EP/ CS/DOPO samples were all decreased. When the mass ratios of CS to DOPO were $1: 1,1: 2$ and $1: 3$, respectively, equivalent to the gradual increase of DOPO content, the $T_{g}$ of EPs gradually decreased. Two aspects for the decrease of $\mathrm{T}_{\mathrm{g}}$ values were concluded: 1) stereo-hindrance of DOPO structure decreased the crosslinking density of EPs (Liu et al. 2014); 2) CS with active $\mathrm{N}-\mathrm{H}$ and -OH bonds could act as chain extender and reduce the crosslinking density of EPs. Meanwhile, when the mass ratio of CS / DOPO was 1:1, 2:1 and $3: 1$, the $\mathrm{T}_{\mathrm{g}}$ of EPs were $132.8^{\circ} \mathrm{C}, 146.8^{\circ} \mathrm{C}$ and $143.7^{\circ} \mathrm{C}$, respectively. It can be seen that the $\mathrm{T}_{\mathrm{g}}$ of EPs increased with the addition of CS. It is particularly noteworthy that compared with the other two samples, when the mass ratio of CS to DOPO was $2: 1$, the $T_{g}$ value of the sample was the highest in CS / DOPO modified EPs. It was conjectured that with the addition of CS and DOPO, the crosslinking density of EPs decreased. However, when the mass ratio of CS / DOPO was $2: 1$, the flame retardant composite system formed a relatively dense cross-linking structure with epoxy resin. This is consistent with the mechanical properties of the materials.

TGA tests were further carried out to study the thermal stability and decomposition behaviors of EP and CS / DOPO modified EP samples. Fig.3 showed the TGA curve of EP, EP / CS, EP / DOPO, and EP / CS / DOPO samples, and the corresponding results were listed in Table 2. It can be seen from Fig. 3 that under $\mathrm{N}_{2}$ atmosphere, the initial decomposition temperature $\left(T_{5} \%\right.$ and the maximum weight loss temperature $\left(T_{\max \%}\right.$ ) of EP were $366.6^{\circ} \mathrm{C}$ and $383.8^{\circ} \mathrm{C}$, respectively. The $T_{5} \%$ and $T_{\max } \%$ of EP/10\% DOPO and EP/ $10 \% \mathrm{CS}$ samples were $285.2^{\circ} \mathrm{C}, 385.6^{\circ} \mathrm{C}$ and $366.3^{\circ} \mathrm{C}, 385.3^{\circ} \mathrm{C}$, respectively. The $\mathrm{T}_{5 \%}$ of all modified EPs is higher than the curing temperature of EP ranged from $100-150^{\circ} \mathrm{C}$, indicating that DOPO, CS or CS / DOPO can meet the solidification condition. The $T_{5 \%}$ of the other samples decreased to varying degrees, but the $T_{\max \%}$ of the other samples did not change much. It can be inferred that the decrease of initial decomposition temperature $T_{g}$ of modified materials was attributed to the addition of DOPO. It can be seen from Fig. 3 that, unlike EP, the pyrolysis process of modified materials had two rapid weight loss stages, $240 \pm 10^{\circ} \mathrm{C}$ and $285 \pm 5^{\circ} \mathrm{C}$, respectively. The main reasons were as follows: on one hand, the thermal decomposition temperature of CS and DOPO is lower than that of EP, it can be assigned to the preferential decompose of CS and DOPO that did not react with EP over EP/CS/DOPO materials during the heating process. On the other hand, with the loading of CS and DOPO, the epoxy groups of the system were correspondingly reduced, thereby reducing the crosslinking density of EP more or less. Except $\mathrm{EP} / 10 \% \mathrm{DOPO}$, the char residues at $750^{\circ} \mathrm{C}$ were all higher than that of EP, indicating that these EPs had superior high temperature stability and better carbonization capacity than EP.

Table 2 Thermal decomposition parameters of EP and EP/CS/DOPO 


\begin{tabular}{|llll|}
\hline Sample & $\mathrm{T}_{5 \%}\left({ }^{\circ} \mathrm{C}\right)$ & $\mathrm{T}_{\max }\left({ }^{\circ} \mathrm{C}\right)$ & Residue at $750{ }^{\circ} \mathrm{C}(\%)$ \\
\hline EP & 366.6 & 383.8 & 17.7 \\
\hline EP/10\% CS & 366.3 & 385.6 & 18.9 \\
\hline EP/10\% DOPO & 285.2 & 384.6 & 16.3 \\
\hline EP/10\% CS1/DOPO1 & 326.6 & 382.4 & 19.7 \\
\hline EP/10\% CS1/DOPO2 & 311.5 & 383.7 & 18.7 \\
\hline EP/10\% CS1/DOPO3 & 305.5 & 382.2 & 19.3 \\
\hline EP/10\% CS2/DOPO1 & 320.5 & 384.5 & 21.6 \\
\hline EP/10\% CS3/DOP01 & 335.8 & 381.3 & 20.2 \\
\hline
\end{tabular}

3.2. Flame retardance of EP composites

\subsubsection{UL-94 tests and LOI}

UL-94 is measured by the length of combustion times and burning dripping at self-extinguishing (Wang et al. 2009). Limiting oxygen index (LOI) refers to the minimum oxygen concentration (volume percentage) that supports the combustion of materials. The test results of flame retardancy of EPs studied by LOI and UL-94 vertical combustion tests were summarized in Table 3. As can be seen from Table 3, all the modified EPs did not obtain V-0 rating when the total addition amount was $8 \%$. However, when the total addition was $10 \%$, EP/10\% DOPO modified EPs passed the V-0 rating. Interestingly, when the mass ratio of CS / DOPO was $1: 2$ or $2: 1$, the modified EPs passed the V-0 rating, but the other mass ratio of CS / DOPO modified EPs only obtained the V-1 or V-2 rating. It indicated that under the premise of a certain total amount of addition with the mass ratio of the two of $1: 2$ or $2: 1$, the synergistic effect of CS and DOPO on EPs was prominent. For LOI tests, the LOI value of EP sample was $22.6 \%$, however, with the incorporation of CS or/and DOPO, there was a improvement on LOI values, especially with the incorporation of CS and DOPO both, the increase of LOI value was considerable. The value of EP/10\% CS1/DOPO2 and EP/10\% CS2/DOPO1 samples reached up to $35.1 \%$ and $34.3 \%$, respectively, and simultaneously obtained $\mathrm{V}-0$ rating. According to the analyses above, it was concluded that when the total addition amount was $10 \%$ and the mass ratios of CS and DOPO were $1: 2$ and $2: 1$, EP could be endowed with good flame retardancy.

Table 3 Formulations of epoxy samples and the results of UL-94 and LOI tests 


\begin{tabular}{|lllllllll|}
\hline Samples & EP & DDM & CS/DOPO & CS & DOPO & LOI & UL-94 & \\
\cline { 2 - 5 } & $(\mathrm{g})$ & $(\mathrm{g})$ & $(\mathrm{wt} / \mathrm{wt})$ & $(\mathrm{g})$ & $(\mathrm{g})$ & $\begin{array}{l}(\%) \\
\pm 0.3 \%)\end{array}$ & Dripping & Rating \\
\hline EP & 25 & 6.5 & - & 0 & 0 & 22.6 & $\mathrm{Y}$ & None \\
\hline EP/8\% CS & 25 & 6.5 & - & 2.74 & 0 & 24.4 & $\mathrm{~N}$ & None \\
\hline EP/8\% DOPO & 25 & 6.5 & - & 0 & 2.74 & 34.2 & $\mathrm{~N}$ & $\mathrm{~V}-1$ \\
\hline EP/8\% CS1/DOPO1 & 25 & 6.5 & $1: 1$ & 1.37 & 1.37 & 31.3 & $\mathrm{~N}$ & $\mathrm{~V}-2$ \\
\hline EP/8\% CS1/DOPO2 & 25 & 6.5 & $1: 2$ & 0.91 & 1.83 & 35.1 & $\mathrm{~N}$ & $\mathrm{~V}-1$ \\
\hline EP/8\% CS2/DOPO1 & 25 & 6.5 & $2: 1$ & 1.83 & 0.91 & 34.3 & $\mathrm{~N}$ & $\mathrm{~V}-1$ \\
\hline EP/8\% CS1/DOPO3 & 25 & 6.5 & $1: 3$ & 0.69 & 2.05 & 34.8 & $\mathrm{~N}$ & $\mathrm{~V}-1$ \\
\hline EP/8\% CS3/DOPO1 & 25 & 6.5 & $3: 1$ & 2.05 & 0.69 & 32.6 & $\mathrm{~N}$ & $\mathrm{~V}-1$ \\
\hline EP/10\% CS & 25 & 6.5 & - & 3.5 & 0 & 23.3 & $\mathrm{~N}$ & $\mathrm{None}$ \\
\hline EP/10\% DOPO & 25 & 6.5 & - & 0 & 3.5 & 30.5 & $\mathrm{~N}$ & $\mathrm{~V}-0$ \\
\hline EP/10\% CS1/DOPO1 & 25 & 6.5 & $1: 1$ & 1.75 & 1.75 & 32.8 & $\mathrm{~N}$ & $\mathrm{~V}-2$ \\
\hline EP/10\% CS1/DOPO2 & 25 & 6.5 & $1: 2$ & 1.17 & 2.33 & 33.7 & $\mathrm{~N}$ & $\mathrm{~V}-0$ \\
\hline EP/10\% CS2/DOPO1 & 25 & 6.5 & $2: 1$ & 2.33 & 1.17 & 32.5 & $\mathrm{~N}$ & $\mathrm{~V}-0$ \\
\hline EP/10\% CS1/DOPO3 & 25 & 6.5 & $1: 3$ & 0.87 & 2.63 & 34.8 & $\mathrm{~N}$ & $\mathrm{~V}-1$ \\
\hline EP/10\% CS3/DOPO1 & 25 & 6.5 & $3: 1$ & 2.63 & 0.87 & 30.2 & $\mathrm{~N}$ & $\mathrm{~V}-1$ \\
\hline
\end{tabular}

\subsubsection{Cone calorimeter}

$\mathrm{CC}$ tests, as one of the most effective bench-scale methods, were employed to assess the combustion behavior of materials. Various parameters can be obtained from the $\mathrm{CC}$ tests, some representative detailed criterions were shown in Table 4 and the curves were illustrated in Fig. 4, respectively. As can be seen, the time for ignitions (TTI) of EP/10\% CS1/DOPO2 and EP/10\% CS2/DOPO1 was longer than that of EP consistently. Mainly due to the presence of unreacted CS and DOPO with EP, which would preferentially decompose into non-combustible gases, such as $\mathrm{H}_{2} \mathrm{O}, \mathrm{NH}_{3}, \mathrm{CO}_{2}$ and $\mathrm{N}_{2}$, diluting the combustible gases on the surface of the material in combustion. Comparison with EP, the PHRR and THR values of EP/10\% CS1/DOPO2 and EP/10\% CS2/DOPO1 decreased, indicating that CS / DOPO increased flame retardancy activity of EP. The Fire Growth Rate Index (FIGRA), as an important parameter for evaluating fire hazard, is calculated by the maximum value of $H R R / t$ and always equal to $P H R R / t_{p}$, which can estimate both the fire spread rate and fire scale. The lower the value of FIGRA can be considered the slower the flame spread and flame growth. It can be seen from Table 4 that the FIGRA values of EP/10\% CS1/DOPO2 and EP/10\% CS2/DOPO1 were significantly lower than that of EP, indicating that the CS / 
DOPO could reduce fire hazard. In addition, it is worth noting that the PHRR, THRP and SPR values of the two modified EPs were smaller than those of EP, especially, TSP decreased by $61.9 \%$ and $71.0 \%$, indicating that the CS / DOPO can not only reduce heat release, but also greatly enhance the smoke inhibition of EP. The possible reason was that the CS / DOPO formed a stable and dense carbon layer during combustion, which hindered the heat transfer inside the samples during ignition and reduced the flue gas release channel, thus achieving the quenching effect. In terms of reducing heat release, $E P / 10 \%$ CS1/DOPO2 had better performance. The av-EHC value of EP was $29.3 \mathrm{MJ} \mathrm{kg}^{-1}$, while the av-EHC values of $\mathrm{EP} / 10 \% \mathrm{CS} 1 / \mathrm{DOPO} 2$ and $\mathrm{EP} / 10 \% \mathrm{CS} 2 / \mathrm{DOPO} 1$ were decreased by $27.6 \%$ and $0.7 \%$, respectively, indicating that the gas phase flame retardancy was more obvious when the mass ratio of CS and DOPO was 1:2. Moreover, compared with EP, the average $\mathrm{CO}_{2}$ yield decreased by $55.4 \%$ for EP/10\% CS1/DOPO2 and $55.0 \%$ for $\mathrm{EP} / 10 \% \mathrm{CS} 2 / \mathrm{DOPO} 1$, while the relative average $\mathrm{CO}$ yield only increased by $6 \%$ and $9 \%$, respectively. The results indicated that the complete combustion degree of the modified EPs significantly reduced.

Furthermore, the flame retardancy related to flame inhibition, charring, and formation of a protective barrier layer were quantify according to the calculation method reported in the literature (Tang et al. 2017). The values of the three main modes of action can be obtained from the following equations (1)(3) and were summarized in Table S1. A significant improvement in the flame-inhibition effect $27.60 \%$ was obtained when the addition amount of CS and DOPO was $10 \%$ with the mass ratio of CS and DOPO of $1: 2$. The reason can be contributed to the obvious quenching effect caused by more PO free radicals released during thermal decomposition by adding more DOPO. Both EP/10\%CS1/DOPO2 and EP/10\% CS2/DOPO1 exhibited higher barrier and protection effects, which were $20.36 \%$ and $36.52 \%$. The better barrier and protection effects of the latter was due to the higher content of CS in it, it was also the reason why EP/10\% CS2/DOPO1 can achieve V-0 rating in the UL-94 tests.

Flame inhibition $=1-\frac{\left.E H C_{(E P}-\text { modified }\right)}{E H C \text { (EP) }}$
Charring effect $=1-\frac{T M L \text { (EP-modified) }}{T M L(E P)}$

Barrier and protective effect $=1-\frac{\left.P H R R_{(E P}-\text { modified }\right) / P H R R(E P)}{\left.T H R_{(E P}-\text { modified }\right)}$

Table 4 The CC test results of EP and its flame-retardant EP samples 


\begin{tabular}{|c|c|c|c|}
\hline \multirow[t]{2}{*}{ Sample } & \multirow[t]{2}{*}{ EP } & \multirow{2}{*}{$\begin{array}{l}\text { EP/10\% } \\
\text { CS1/DOPO2 }\end{array}$} & \multirow{2}{*}{$\begin{array}{l}\text { EP/10\% } \\
\text { CS2/DOPO1 }\end{array}$} \\
\hline & & & \\
\hline Time for ignitions(s) & 59.0 & 81.0 & 87.0 \\
\hline \multicolumn{4}{|l|}{$(\mathrm{TTI})(\mathrm{s})$} \\
\hline Time to peaks (s) & 130.0 & 120.0 & 130.0 \\
\hline \multicolumn{4}{|l|}{$t_{p}(s)$} \\
\hline Peak heat release rate $(\mathrm{PHRR})\left(\mathrm{KW} \cdot \mathrm{m}^{-2}\right)$ & 1063.1 & 783.3 & 770.4 \\
\hline Fire growth rate index (FIGRA) & 8.2 & 6.5 & 5.9 \\
\hline Peak smoke produce rate (PSPR) $\left(\mathrm{m}^{2} \cdot \mathrm{s}^{-1}\right)$ & 0.5 & 0.4 & 0.3 \\
\hline Total smoke release & 71.4 & 27.2 & 20.7 \\
\hline \multicolumn{4}{|l|}{$(\mathrm{TSP})\left(\mathrm{m}^{2}\right)$} \\
\hline Total heat release $(\mathrm{THR})\left(\mathrm{MJ} \cdot \mathrm{m}^{-2}\right)$ & 94.8 & 69.7 & 85.4 \\
\hline 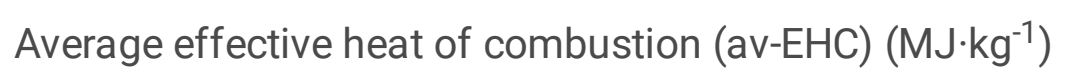 & 29.3 & 21.2 & 29.1 \\
\hline Average $\mathrm{CO}$ yield & 0.33 & 0.35 & 0.36 \\
\hline \multicolumn{4}{|l|}{$(\operatorname{av}-\mathrm{COY})\left(\mathrm{kg} \cdot \mathrm{kg}^{-1}\right)$} \\
\hline Average $\mathrm{CO}_{2}$ yield $\left(\right.$ av- $\left.\mathrm{CO}_{2} \mathrm{Y}\right)\left(\mathrm{kg} \cdot \mathrm{kg}^{-1}\right)$ & 7.38 & 3.29 & 3.32 \\
\hline Char residue (\%) & 8.9 & 16.4 & 12.6 \\
\hline Total mass loss & 91.1 & 83.6 & 87.4 \\
\hline (TML) (\%) & & & \\
\hline
\end{tabular}

\subsection{Flame-retardant mechanism}

\subsubsection{Char residues analyses after CC tests}

To disclose the flame-retardant mechanism in the condensed phase, element composition, chemical structure and morphology of char residues surface were investigated by EDX, FTIR, Raman and SEM. Firstly, the elemental composition of the surface of the char residuals without crushing was studied, the results were shown in Fig. S1. For EP/10\% CS1/DOPO2, the content of carbon decreased, but the content of oxygen and phosphorus increased significantly in comparison with EP, indicating that there were a large number of phosphorus-containing oxides on the surface of residual carbon. For EP/10\% CS2/DOP01 samples, the carbon content increased, and the phosphorus content of oxygen and phosphorus was lower than EP, indicating that the formed char residual was mainly graphitized carbon, 
which played a flame retardancy effect, which was consistent with the results of Raman. It was worth noting that no nitrogen was found on the char residues surface of all samples, indicating that nitrogen elements on the surface were completely converted into gaseous in the form of small molecules, such as $\mathrm{N}_{2}$ and $\mathrm{NO}_{2}$, etc.

Further EDX elemental mapping analysis was conducted on the cross-section of char residual, and the detailed distribution of elements was shown in Fig. 5. As seen in Fig. 5, all elements except carbon were increased and distributed evenly. That proved the presence of carbon, nitrogen and oxygen in the chars of EPs. In addition, phosphorus was uniformly distributed in the char residuals of EP/10\% CS1/DOPO2 and $\mathrm{EP} / 10 \% \mathrm{CS} 2 / \mathrm{DOPO} 1$, which improved the heat resistance and oxidation resistance of the char residuals.

Fig. 6 showed digital and SEM images of char residues after CC test. As shown in Fig. 6 (a1-a4), the char residuals of EP showed that there were only a small amount of char residuals left on the margin of the base plate, along with a large amount holes in its microstructure, which did not have the ability to protect the matrix from combustion. While the char residuals of EP/10\% CS1/DOPO2 and EP/10\% CS2/DOPO1 increased by $84.3 \%$ and $41.6 \%$ when compared with EP, respectively, and exhibited more uniform carbon layer with relatively smaller holes in the microstructure. In addition, the carbon layer of EP was discontinuous and loose, while the carbon layer of the modified EPs showed a more continuous and dense structure. The dense carbon layer can be used as a protective layer to prevent the continuous combustion of the matrix. At the same time, the char residuals particles of EP were a dispersion state, while the char residuals particles of modified EPs had good agglomeration. The agglomeration of char residuals particles of EP/10\% CS2/DOPO1 was more obvious among them.

It is known that the barrier effect of condensed phase is not only affected by its quantity, but also closely related to its structure. Raman spectroscopy is an effective technique for analyzing the internal structure of carbonaceous materials after combustion. As shown in Fig. 7, two remarkable peaks at 1360 and 1590 $\mathrm{cm}^{-1}$ in all spectra are belong to $\mathrm{D}$ band (vibrations of amorphous carbon atoms) and $\mathrm{G}$ band (vibration of $\mathrm{sp}^{2}$-hybridized carbon atoms), respectively. Generally, the ratio of the integrated intensities of $D$ to $G$ band $\left(\mathrm{I}_{\mathrm{D}} / \mathrm{I}_{\mathrm{G}}\right)$ is usually used to measure the degree of graphitization. The lower the $\mathrm{I}_{\mathrm{D}} / \mathrm{I}_{G}$ value, the higher the graphitization degree and the better the flame retardancy. As seen, the values of $I_{D} / I_{G}$ follow the sequence of $\mathrm{EP}$ (3.93) > EP/10\% CS1/DOPO2 (2.88) > EP/10\% CS2/DOPO1 (2.65), indicating that the graphitization degree of modified EPs had significantly increased. This denser char layer can better hinder the escape of flammable gases and entrance of oxygen in the condensed phase during combustion, thus protecting the inner materials to reduce decomposition.

The chemical structure of char residual was studied by FTIR. As shown in Fig. 8, the main absorption peaks were observed at $2927 \mathrm{~cm}^{-1}, 1607 \mathrm{~cm}^{-1}$ and $1080 \mathrm{~cm}^{-1}$, which belonged to the vibration of aromatic rings ( $\mathrm{Li}$ and Yang 2014). By comparison with EP, the new peaks at 1236 and $1040 \mathrm{~cm}^{-1}$ were attributed to the stretching vibration of $\mathrm{P}=\mathrm{O}$ and $\mathrm{P}-\mathrm{O}-\mathrm{C}$, and the absorption peaks of $\mathrm{C}-\mathrm{P}$ and phenol were observed at 1510 and $754 \mathrm{~cm}^{-1}$, respectively (Zhang et al. 2012a; Yang et al. 2016). The above results showed that the char residue was mainly composed of graphite-like compounds and organic phosphorus compounds. 
Simultaneously, the chemical compositions of char residues for EP, EP/10 \%CS1/DOPO2 and EP/10 $\% C S 2 / D O P 01$ after CC test were further analyzed by XPS. The XPS spectra and the atom percent of $\mathrm{C}_{1 \mathrm{~s}}$, $\mathrm{N}_{1 \mathrm{~s}}, \mathrm{O}_{1 \mathrm{~s}}$ and $\mathrm{P}_{2 \mathrm{~s}}$ for the char residues of EPs were shown in Fig. 9 and Table S2, respectively. In the $\mathrm{C}_{1 \mathrm{~s}}$ spectrum, there were three kinds of carbon binding states in the three samples, among which the peak at $287.7 \mathrm{eV}$ belongs to $\mathrm{C}=\mathrm{C}$ and $\mathrm{C}=\mathrm{O}$ bonds, the peak at $285.8 \mathrm{eV}$ belongs to $\mathrm{C}-\mathrm{O}$ and $\mathrm{C}-\mathrm{N}$ bonds, and the peak at $284.7 \mathrm{eV}$ belongs to $\mathrm{C}-\mathrm{H}$ and $\mathrm{C}-\mathrm{C}$ bonds in aliphatic and aromatic components ( $\mathrm{Li}$ et al. 2019). Moreover, it can be clearly seen that the peak at $285.8 \mathrm{eV}$ of the two modified EPs increased compared with EP, suggesting that more cross-linked carbon composed of $\mathrm{C}-\mathrm{O}$ and $\mathrm{C}-\mathrm{N}$ was formed in the residual carbon. In the $\mathrm{N}_{1 \mathrm{~s}}$ spectrum, all three samples presented two peaks at 400.3 and $398.7 \mathrm{eV}$, wherein the former was the contribution of $\mathrm{N}-\mathrm{H}$ bond, and the latter was assigned to $\mathrm{C}-\mathrm{N}$ bond (Wang et al. 2010). In the $\mathrm{O}_{1 \mathrm{~s}}$ spectrum, similarly, all three samples had peaks at $533.3 \mathrm{eV}$ and $532.3 \mathrm{eV}$, the former was attributed to the $\mathrm{C}-\mathrm{OH}$ and $\mathrm{C}-\mathrm{O}-\mathrm{C}$ groups and the latter belonged to $\mathrm{C}=\mathrm{O}$ (Zhang et al. 2012b). However, the modified EPs both had a larger peak at $533.3 \mathrm{eV}$ than that of EP, which was due to the formation of C-O-P or C-O-C, P-O-P groups in the char residues of the modified EPs. In the $\mathrm{P}_{2 s}$ spectrum, there were two new peaks, 134.4 and $133.3 \mathrm{eV}$, in the char residues of modified EPs (Huang et al. 2018; Sun et al. 2016), which assigned to P-O-P, P-O-C and/or $\mathrm{PO}^{3-}$ group in phosphate. This further indicated the formation of phosphate-containing compounds in the char residuals, which were covered on the surface of the materials and prevented the further combustion.

\subsubsection{TG-FTIR analysis of EP and modified EPs samples}

In order to evaluate comprehensively the influence of the CS / DOPO on the thermal stability of EP composites, TG-FTIR spectra were applied to further disclose the decomposition behavior of the modified EPs under programmed heating process. The detailed characteristics of each TG-FTIR spectrum for EP, $\mathrm{EP} / 10 \% \mathrm{CS} 1 / \mathrm{DOPO} 2$ and EP/ $10 \% \mathrm{CS} 2 / \mathrm{DOPO} 1$ obtained at $100{ }^{\circ} \mathrm{C}, 200{ }^{\circ} \mathrm{C}, 300{ }^{\circ} \mathrm{C}, 400{ }^{\circ} \mathrm{C}, 500{ }^{\circ} \mathrm{C}$, $600{ }^{\circ} \mathrm{C}, 700{ }^{\circ} \mathrm{C}$ and $800{ }^{\circ} \mathrm{C}$ were shown in Fig. 10. The 3D TG-FTIR images of EP, EP/10\% CS1/DOPO2 and $\mathrm{EP} / 10 \% \mathrm{CS} 2 / \mathrm{DOPO} 1$ at various temperatures were shown in Fig. S2. It can be seen that EP produced more $\mathrm{CO}_{2}$ than other three sample and the absorption peak of phosphorus-containing substances can be clearly observed in EP/10\% CS1/DOPO2 and EP/10\% CS2/DOPO1.

As shown in Fig. 10, all EPs exhibited the characteristic absorption peaks of nonflammable gases, such as $\mathrm{H}_{2} \mathrm{O}$ and $\mathrm{CO}_{2}$, which could be demonstrated by the broad bands at $3500-4000$ and $2300-2390 \mathrm{~cm}^{-1}$, respectively (Wang et al. 2011a; Wen et al. 2018). It can be seen that in terms of carbon dioxide release, EP released the most. Compared with EP/10\% CS1/DOPO2, EP/10\% CS2/DOPO1 released more $\mathrm{CO}_{2}$, which was coincided with the results of $\mathrm{CC}$ tests. Furthermore, hydrocarbons can be clearly identified at the broad bands at $600-700,1100-1500$, and $2900-3100 \mathrm{~cm}^{-1}$ between $400{ }^{\circ} \mathrm{C}$ and $800{ }^{\circ} \mathrm{C}$, as the peak at about $661 \mathrm{~cm}^{-1}$ attributed to $=\mathrm{CH}$ - bonds, peaks at $1180 \mathrm{~cm}^{-1}, 1460 \mathrm{~cm}^{-1}$ and $2972 \mathrm{~cm}^{-1}$ belonged to the $\mathrm{CH}_{3}$ bonds, peak at $2927 \mathrm{~cm}^{-1}$ assigned to $-\mathrm{CH}_{2}$ - bonds (Wang et al. 2011b; Wu et al. 2011). In addition, some sharp peaks appeared in the range of $1550-1800 \mathrm{~cm}^{-1}$, which might be carbonyl-containing 
compounds such as carboxylic acids $\left(1706 \mathrm{~cm}^{-1}\right)$, ketones $\left(1720 \mathrm{~cm}^{-1}\right)$ and aldehydes $\left(1738 \mathrm{~cm}^{-1}\right)($ Yan et al. 2018).

Significant difference was observed compared to EP and EP/10\% CS, as shown in Fig. 10, after fortified with CS / DOPO for EP, the peak at about $1129 \mathrm{~cm}^{-1}$ for EP/10\% CS1/DOPO2 and EP/10\% CS2/DOPO1 was attributed to the Ph-P bond (Xu et al. 2016). Moreover, the peak at about $1260 \mathrm{~cm}^{-1}$ assigned to the stretching vibration of $\mathrm{P}=0$, which was probably overlapped with the characteristic absorbance of ether bonds. A weak absorption peak at $1642 \mathrm{~cm}^{-1}$ was the stretching vibration of $\mathrm{P}-\mathrm{OH}$ (Yuan et al. 2018). On the basis of the analysis above, a variety of phosphorus-containing compounds were generated during the thermal decomposition process for modified EPs, which can increase the flame retardancy efficiency of EP significantly. It is worth noting that compared with EP/10\% CS1/DOPO2, most of the absorption peaks of nonflammable gas for $\mathrm{EP} / 10 \% \mathrm{CS} 2 / \mathrm{DOPO} 1$ were larger, so it was speculated that $\mathrm{EP} / 10 \%$ CS2/DOPO1 was mainly gas-phase flame retardancy effect while EP/10\% CS1/DOPO2 was mainly condensed-phase flame retardancy effect, which was consistent with the results of CC tests.

In order to explore the time when these EPs began to decompose into gas in the process of thermal decomposition, the curve was made with time as abscissa and infrared absorption intensity as ordinate, simultaneously the first derivative curve was drawn. seen in the Fig. S3, the pyrolysis products of EP began to release at approximately 31.2 min. Surprisingly, the time of EP/10\% CS1/DOPO2 and EP/10\% CS2/DOPO1 began to release pyrolysis products almost identical, which were $30.3 \mathrm{~min}$ and $30.2 \mathrm{~min}$, respectively, a little less than that of EP. The results showed that the thermal stability of the modified EPs slightly decreased after adding CS / DOPO, which was consistent with the test results of $\mathrm{T}_{\mathrm{g}}$ and TGA.

\subsection{Mechanical properties}

The mechanical properties of materials are important in some areas, so it is necessary to study the mechanical properties of modified EPs and make corresponding analysis. The mechanical properties were analyzed from three indexes: tensile strength, flexural strength and izod impact strength. The results were summarized in Fig. 11. As can be seen from the figure that the tensile strength, flexural strength and izod impact strength of EP were $54 \mathrm{M} \cdot \mathrm{Pa}, 86 \mathrm{M} \cdot \mathrm{Pa}$ and $21 \mathrm{KJ} \cdot \mathrm{m}^{-2}$, respectively. Compared with $\mathrm{EP}$, the tensile strength, flexural strength and izod impact strength of CS / DOPO modified EPs increased, especially the flexural strength. Compared with EP, the flexural strengths of EP/10\% CS and EP/10\% DOPO increased by $2.3 \%$ and $7.0 \%$, while, EP/10\% CS1/DOPO2 and EP/10\% CS2/DOPO1 increased by $36.0 \%$ and $38.4 \%$, respectively. The flexural strength of CS / DOPO modified EP was significantly higher than those of $\mathrm{EP} / 10 \% \mathrm{CS}$ and $\mathrm{EP} / 10 \% \mathrm{DOPO}$ under the same addition amount in EP, which can be contributed to the synergistic effect of CS and DOPO in EP when the mass ratio was $1: 2$ or $2: 1$. The main reason was that there were $-\mathrm{NH}_{2}$ and $-\mathrm{OH}$ active bonds in $\mathrm{CS}$ and $\mathrm{P}-\mathrm{H}$ active bonds in DOPO. On the one hand, $-\mathrm{NH}_{2}$ and $-\mathrm{OH}$ bonds would form intramolecular and intermolecular hydrogen bonds, increasing the compatibility of CS and DOPO with EP. On the other hand, these active groups would react with epoxy groups in EP to undergo ring-opening reaction, which enhanced the formation of cross-linking network in 
the curing process. What's more, the $\pi-\pi$ stacking among the aromatic rings were also conducive to improving its mechanical strength. The possible chemical reactions were shown in Scheme 1.

\section{Conclusions}

In this work, the direct compound of biomass and DOPO was used to modify the EP by a solution blending method. The results showed that the flame retardancy of EP was improved by adding CS / DOPO, especially when the total amount of CS / DOPO was $10 \%$ and the mass ratio of CS and DOPO was $1: 2$ and 2:1, both modified EPs obtained V-0 rating, and LOI increased from $22.6 \%$ for EP to $33.7 \%$ and $32.5 \%$, respectively. At the same time, the PHRR, THR, PSPR and TSP values of EP/10\% CS1/DOPO2 and $\mathrm{EP} / 10 \% \mathrm{CS} 2 / \mathrm{DOPO} 1$ decreased. It showed that under a certain mass ratio, the relative properties of the composite can be greatly amplified by simply mixing the functional materials. In comparison with each other, the flame retardancy mechanism of EP/10\% CS1/DOPO2 and EP/10\% CS2/DOPO1 tended to be in gas phase and in condensed phase, respectively. The general flame retardancy mechanism was summarized as follows according to the results of CC, FTIR, SEM, EDX, TG-FTIR, etc. 1) part of DOPO and CS that didn't involve in curing process was preferentially decomposed into some non-combustible gases such as $\mathrm{CO}_{2}$ and $\mathrm{NH}_{3}$ during in the early stage, diluting the combustible gases; 2) DOPO released Pcontaining radicals during the pyrolysis process, which helped to capture free radicals of chain reaction; 3 ) the obstructing function on heat transfer of the dense char residue. In the meantime, the mechanical properties of EPs did not decrease but increased, especially the flexural strength. Therefore, under the $10 \%$ total addition amount with the mass ratio of CS and DOPO of $1: 2$ or $2: 1$, the EPs were endowed with good flame retardancy and mechanical properties.

\section{Declarations}

Funding: This study was funded by Hubei provincial science and technology department (2018ACA158).

Conflicts of interests: All authors certify that they have no affiliations with or involvement in any organization or entity with any financial interest or non-financial interest in the subject matter or materials discussed in this manuscript.

Availability of data and material: All data generated or analyzed during this study were included in this published article (and its supplementary information files).

Code availability: No software application or custom code.

Authors' contributions: Junjie Wang, synthesis, writing and analysis; Xinyu Wang, characterization; Chengyu Zhou, analysis; Zhiquan Pan, analysis; Hong Zhou, Design and revise of the work.

\section{References}


Ai YF, Xia L, Pang FQ, Xu YL, Zhao HB, Jian RK Yuanfang A, Long X, Fuqu P, Yanlian X, Haibo Z, Rongkun $J(2020)$ Mechanically strong and flame-retardant epoxy resins with anti-corrosion performance. Compos Part B-Eng 193: 108019. doi:10.1016/j.compositesb.2020.108019

Chen XL, Liu L, Jiao CM (2015) Influence of Iron Oxide Brown on Smoke-Suppression Properties and Combustion Behavior of Intumescent Flame-Retardant Epoxy Composites. Adv Polym Tech 34(4): 21516. doi:10.1002/adv.21516

Chen R, Luo ZJ, Yu XJ, Tang H, Zhou Y, Zhou H (2020) Synthesis of chitosan-based flame retardant and its fire resistance in epoxy resin. Carbohyd Polym 245: 116530. doi:10.1016/j.carbpol.2020.116530

Goda ES, Elella MHA, Hong SE, Pandit B, Yoon KR, Gamal H (2021) Smart flame retardant coating containing carboxymethyl chitosan nanoparticles decorated graphene for obtaining multifunctional textiles. Cellulose 28(8): 5087-5105. doi: 10.1007/s10570-021-03833-7

Hoqani HASA, AL-Shaqsi N, Hossaina MA, Sibani MAA (2020) Isolation and optimization of the method for industrial production of chitin and chitosan from Omani shrimp shell. Carbohyd Res 492: 108001. doi:10.1016/j.carres.2020.108001

Huang HW, Dong DX, Li WJ, Zhang XY, Zhang L, Chen Y, Sheng XX, Lu X (2020) Synergistic effect of MXene on the flame retardancy and thermal degradation of intumescent flame retardant biodegradable poly (lactic acid) composites. Chinese J Chem Eng 28: 1981-1993. doi:10.1016/j.cjche.2020.04.014

Huang WJ, He WT, Long J, Yan W, He M, Qin SH, Yu J (2018) Highly efficient flame-retardant glass-fiberreinforced polyamide 6T system based on a novel DOPO-based derivative: Flame retardancy, thermal decomposition, and pyrolysis behavior. Polym Degrad Stabil 148: 26-41.

doi:10.1016/j.polymdegradstab.2018.01.008

Kandola BK, Biswas B, Price D, Horrocks AR (2010) Studies on the effect of different levels of toughener and flame retardants on thermal stability of epoxy resin. Polym Degrad Stabil 95(2): 144-152. doi:10.1016/j.polymdegradstab.2009.11.040

Kim UJ, Kim HJ, Choi JW, Kimura S, Wada M (2017) Cellulose-chitosan beads crosslinked by dialdehyde cellulose. Cellulose 24(12): 5517-5528. doi:10.1007/s10570-017-1528-y

Liu L, Chen XL, Jiao CM (2015) Influence of ferrocene on smoke suppression properties and combustion behavior of intumescent flame-retardant epoxy composites. J Therm Anal Calorim 122(1): 437-447. doi:10.1007/s10973-015-4928-y

Li LY, Chen GH, Liu W, Li JF, Zhang S (2009) The anti-dripping intumescent flame retardant finishing for nylon-6,6 fabric. Polym Degrad Stabil 94(6): 996-1000. doi:10.1016/j.polymdegradstab.2009.02.009

Liu YL, He JY, Yang RJ (2016) The Thermal Properties and Flame Retardancy of 9,10-Dihydro-9-oxa-10phosphaphenanthrene 10-Oxide (DOPO)-Mg/Polyisocyanurate-Polyurethane Foam Composites. B Chem 
Soc Jpn 89(7): 779-785. doi:10.1246/bcsj.20160064

Li JL, Wang C, Lu KY (2019) Enhanced cryogenic mechanical properties and liquid oxygen compatibility of DOPO-containing epoxy resin reinforced by epoxy-grafted polysiloxane. Polym Bull 77(7): 3429-3442. doi:10.1007/s00289-019-02931-8

Liu H, Wang XD, Wu DZ (2014) Novel cyclotriphosphazene-based epoxy compound and its application in halogen-free epoxy thermosetting systems: Synthesis, curing behaviors, and flame retardancy. Polym Degrad Stabil 103: 96-112. doi: 10.1016/j.polymdegradstab.2013.02.008

Li ZQ, Yang RJ (2014) Study of the synergistic effect of polyhedral oligomeric octadiphenylsulfonylsilsesquioxane and 9,10-dihydro-9-oxa-10-phosphaphenanthrene-10-oxide on flameretarded epoxy resins. Polym Degrad Stabil 109: 233-239. doi:10.1016/j.polymdegradstab.2014.07.024

Lai XJ, Zeng XR, Li HQ, Liao F, Yin CY, Zhang HL (2011) Synergistic Effect of Phosphorus-Containing Montmorillonite with Intumescent Flame Retardant in Polypropylene. J Macromol Sci B 51(6): 1186-1198. doi:10.1080/00222348.2011.625909

Netkueakul W, Fischer B, Walder C, Nüesch F, Rees M, Jovic M, Gaan S, Jacob P, Wang J (2020) Effects of Combining Graphene Nanoplatelet and Phosphorous Flame Retardant as Additives on Mechanical Properties and Flame Retardancy of Epoxy Nanocomposite. Polymers-Basel 12(10): 2349. doi:10.3390/polym12102349

Pan HF, Wang W, Pan Y, Zeng WR, Zhan J, Song L, Yuan Hu, Liew KM (2015) Construction of layer-bylayer assembled chitosan/titanate nanotubes based nanocoating on cotton fabrics: flame retardant performance and combustion behavior. Cellulose 22(1): 911-923. doi:10.1007/s10570-014-0536-4

Sun F, Yu T, Hu CQ, Li Y (2016) Influence of functionalized graphene by grafted phosphorus containing flame retardant on the flammability of carbon fiber/epoxy resin (CF/ER) composite. Compos Sci Technol 136: 76-84. doi:10.1016/j.compscitech.2016.10.002

Tang S, Qian LJ, Liu XX, Dong YP (2016) Gas-phase flame-retardant effects of a bi-group compound based on phosphaphenanthrene and triazine-trione groups in epoxy resin. Polym Degrad Stabil 133: 350357. doi:10.1016/j.polymdegradstab.2016.09.014

Tang S, Wachtendorf V, Klack P, Qian LJ, Dong YP, Schartel B (2017) Enhanced flame-retardant effect of a montmorillonite/phosphaphenanthrene compound in an epoxy thermoset. RSC Adv 7(2): 720-728. doi:10.1039/c6ra25070j

Tang H, Zhu ZM, Chen R, Wang JJ, Zhou H (2019) Synthesis of DOPO-based pyrazine derivative and its effect on flame retardancy and thermal stability of epoxy resin. Polym Advan Technol 30: 1-9. doi:10.1002/pat.4674 
Wang QF, Shi WF Qingfeng W, Wenfang S (2006) Synthesis and thermal decomposition of a novel hyperbranched polyphosphate ester used for flame retardant systems. Polym Degrad Stabil 91(6): 12891294. doi:10.1016/j.polymdegradstab.2005.09.001

Wen Y, Cheng Z, Li WX, Li Z, Liao DJ, Hu XP, Pan N, Wang DY, Hull TR (2018) A novel oligomer containing DOPO and ferrocene groups: Synthesis, characterization, and its application in fire retardant epoxy resin. Polym Degrad Stabil 156(10): 111-124. doi:10.1016/j.polymdegradstab.2018.08.010

Wang X, Hu Y, Song L, Xing WY, Lu HD (2011a) Thermal degradation mechanism of flame retarded epoxy resins with a DOPO-substitued organophosphorus oligomer by TG-FTIR and DP-MS. J Anal Appl Pyrol 92(1): 164-170. doi:10.1016/j.jaap.2011.05.006

Wang X, Hu Y, Song L, Xing WY, Lu HD, Lv P, Jie GX (2010) Flame retardancy and thermal degradation mechanism of epoxy resin composites based on a DOPO substituted organophosphorus oligomer. Polymer 51(11): 2435-2445. doi:10.1016/j.polymer.2010.03.053

Wang H, Li Shan, Zhu ZM, Yin XZ, Wang LX, Weng YX, Wang XY (2020) A novel DOPO-based flame retardant containing benzimidazolone structure with high charring ability towards low flammability and smoke epoxy resins. Polym Degrad Stabil 109426. doi:10.1016/j.polymdegradstab.2020.109426

Wu K, Shen MM, Hu Y, Xing WY (2011) Thermal degradation and intumescent flame retardation of cellulose whisker/epoxy resin composite. J Therm Anal Calorim 104(3): 1083-1090. doi:10.1007/s10973011-1380-5

Wang X, Song L, Xing WY, Lu HD, Hu Y (2011b) A effective flame retardant for epoxy resins based on poly(DOPO substituted dihydroxyl phenyl pentaerythritol diphosphonate). Mater Chem Phys 125(3), 536541. doi:10.1016/j.matchemphys.2010.10.020

Wang Y, Zhang F, Chen XL, Jin Y, Zhang J (2009) Burning and dripping behaviors of polymers under the ul94 vertical burning test conditions. Fire Mater 34(4): 203-215. doi:10.1002/fam.1021

Xu ZS, Deng N, Yan L, Chu ZY (2018) Functionalized multiwalled carbon nanotubes with monocomponent intumescent flame retardant for reducing the flammability and smoke emission characteristics of epoxy resins. Polym Advan Technol 2018: 1-12. doi:10.1002/pat.4420

Xie WQ, Huang SW, Tang DL, Liu SM, Zhao JQ (2020) Synthesis of a furfural-based DOPO-containing cocuring agent for fire-safe epoxy resins. RSC Adv 10(4): 1956-1965. doi:10.1039/c9ra06425g

Xu MJ, Xu GR, Leng Y, Li Bin (2016) Synthesis of a novel flame retardant based on cyclotriphosphazene and DOPO groups and its application in epoxy resins. Polym Degrad Stabil 123: 105-114. doi:10.1016/j.polymdegradstab.2015.11.018

Yuan Y, Ma C, Shi YQ, Song L, Hu Y, Hu WZ (2018) Highly-efficient reinforcement and flame retardancy of rigid polyurethane foam with phosphorus-containing additive and nitrogen-containing compound. Mater 
Yang S, Wang J, Huo SQ, Wang M, Wang JP, Zhang B (2016) Synergistic flame-retardant effect of expandable graphite and phosphorus-containing compounds for epoxy resin: Strong bonding of different carbon residues. Polym Degrad Stabil 128: 89-98. doi:10.1016/j.polymdegradstab.2016.03.017

Yan W, Zhang MQ, Yu J, Nie SQ, Zhang DQ, Qin SH (2018) Synergistic Flame-retardant Effect of Epoxy Resin Combined with Phenethyl-bridged DOPO Derivative and Graphene Nanosheets. Chinese J Polym Sci 37: 79-88. doi:10.1007/s10118-019-2175-6

Zou JH, Duan HJ, Chen YS, Ji S, Cao JF, Ma HR (2020) A P/N/S-containing high-efficiency flame retardant endowing epoxy resin with excellent flame retardance, mechanical properties and heat resistance. Compos Part B-Eng 199: 108228. doi:10.1016/j.compositesb.2020.108228

Zhang WC, Li XM, Fan HB, Yang RJ (2012) Study of the synergistic effect of silicon and phosphorus on the blowing-out effect of epoxy resin composites. Polym Degrad Stabil 97(6): 1041-1048.

doi:10.1016/j.polymdegradstab.2012.03.008

Zhang WC, Li XM, Li LM, Yang RJ (2012) Study on mechanism of phosphorus-silicon synergistic flame retardancy on epoxy resins. Polym Degrad Stabil 97(11): 2241-2248.

doi:10.1016/j.polymdegradstab.2012.08.002

\section{Scheme}

Please see the Supplementary Files for the Scheme 1.

\section{Figures}



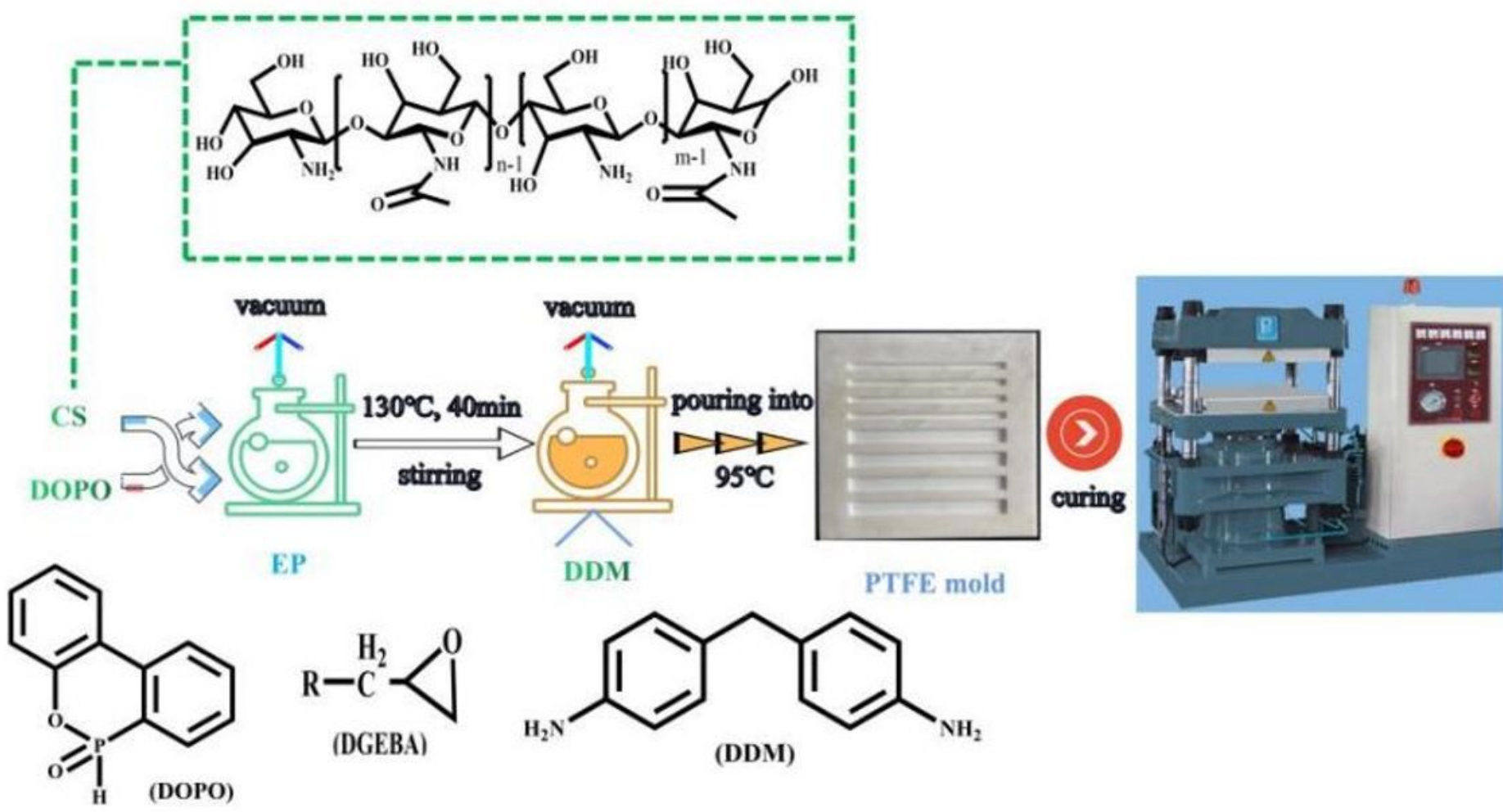

DDM

PTFE mold

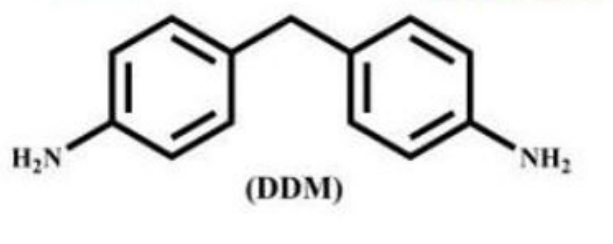

Figure 1

The preparation process of EP and the modified EPs 


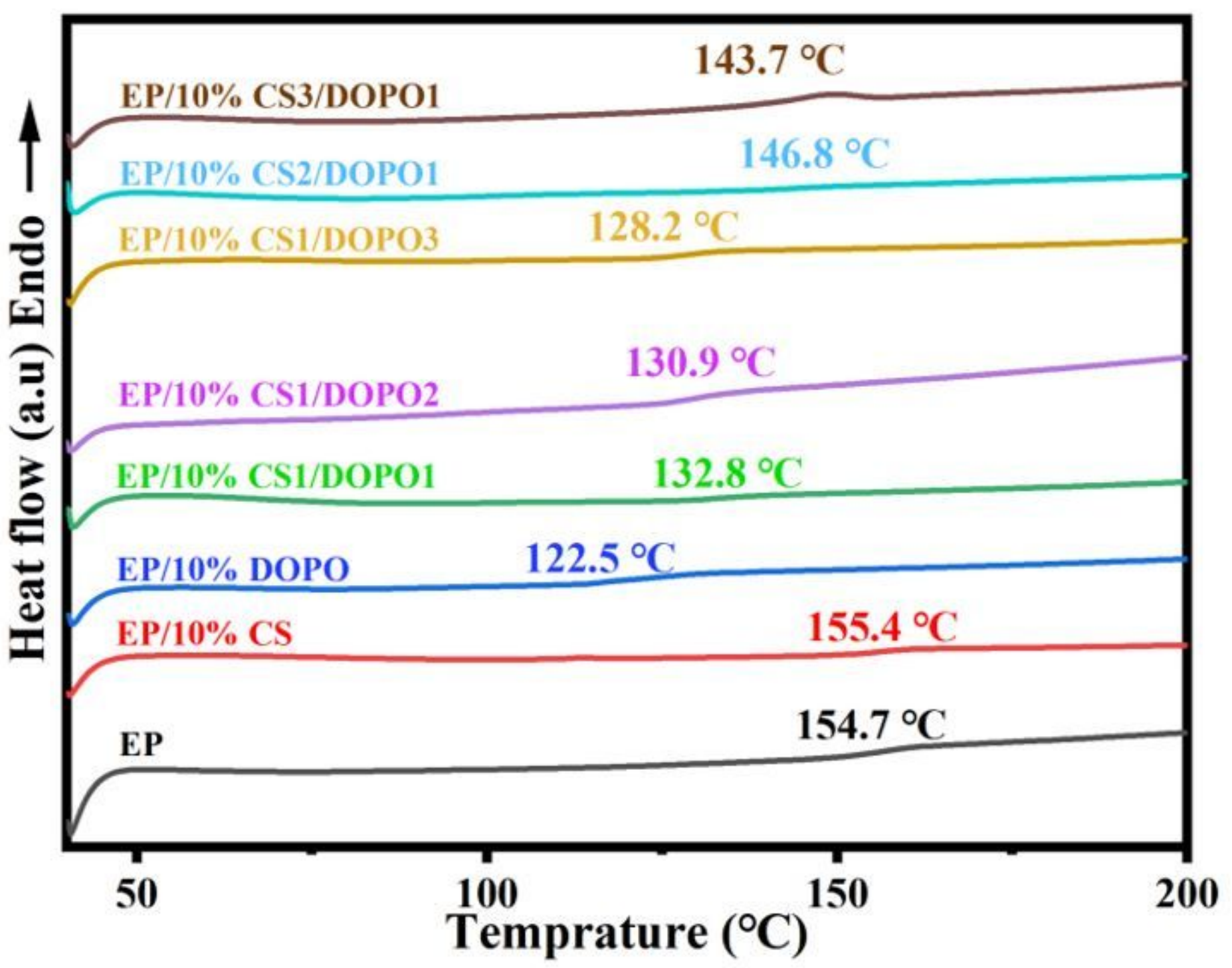

Figure 2

DSC curves of EP and EP/CS/DOPO materials 

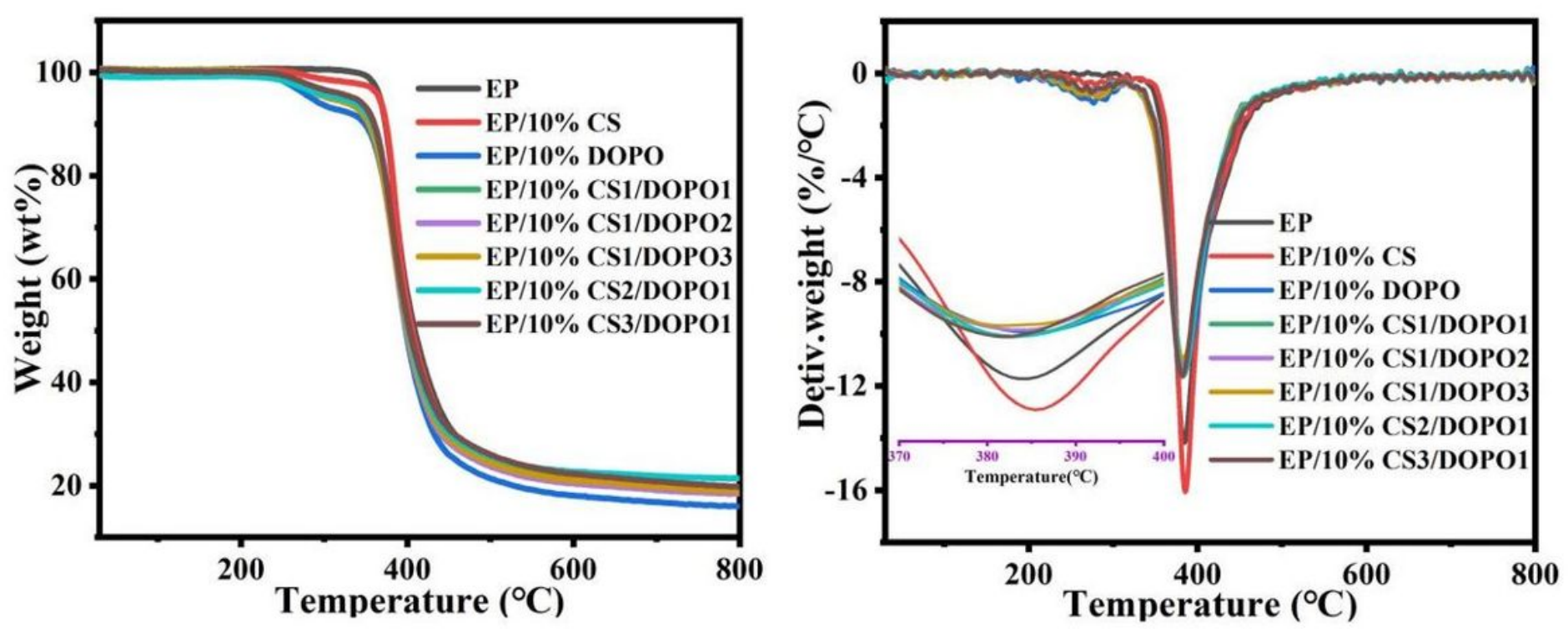

Figure 3

TG curves of epoxy thermosets under nitrogen atmosphere 

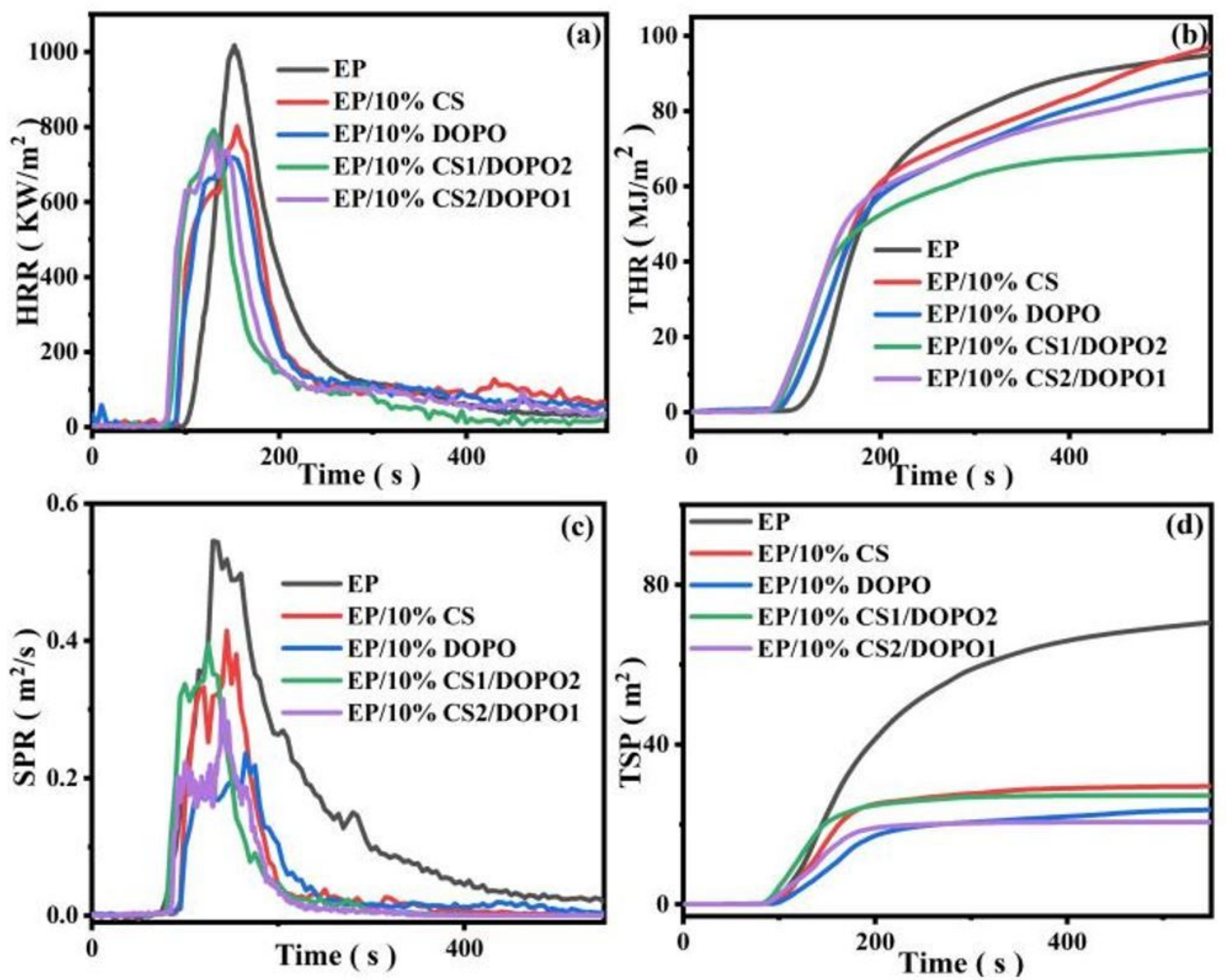

Figure 4

The curves of HRR (a), THR (b), SPR (c) and TSR (d) of EP and modified EPs 


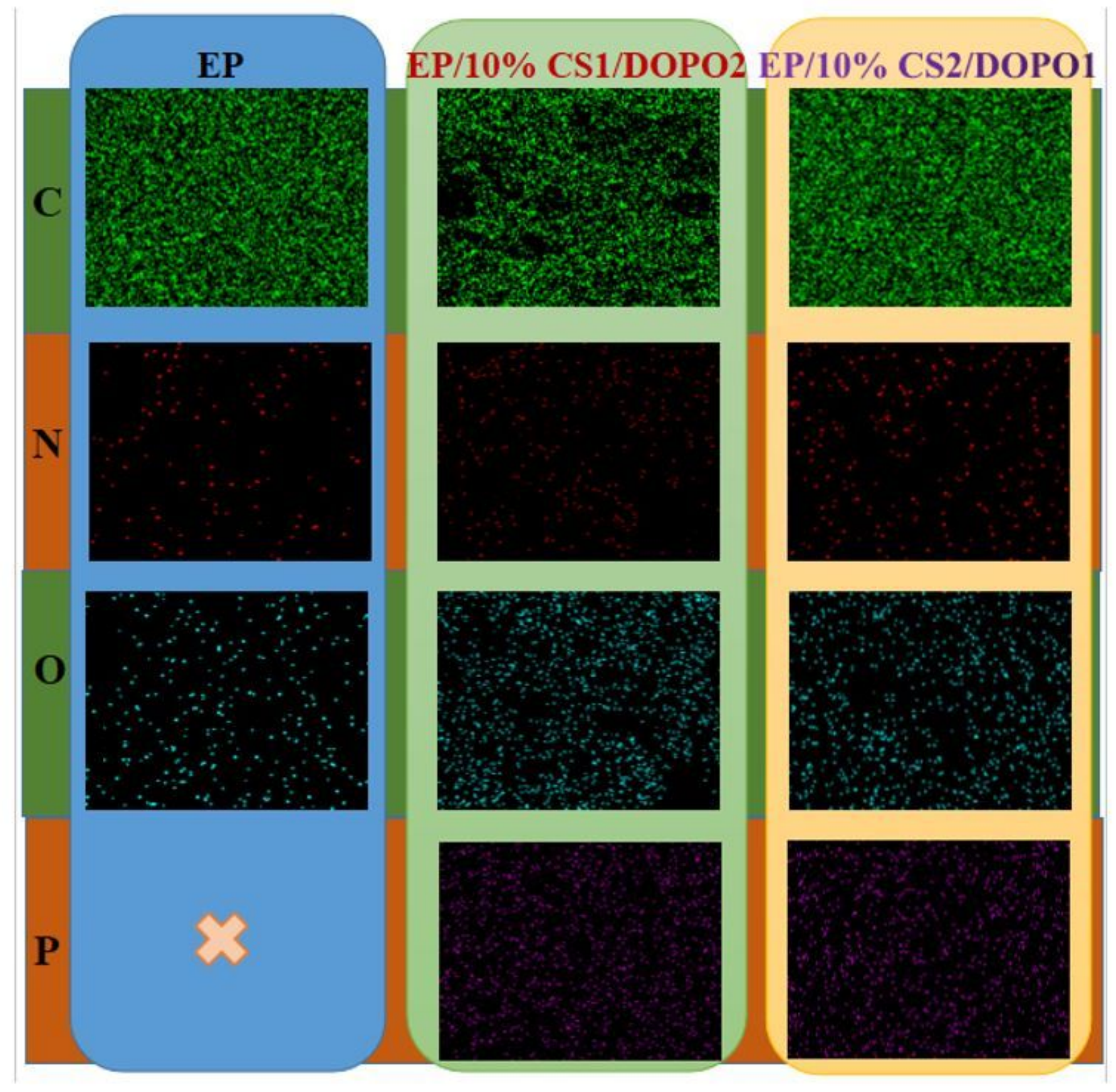

Figure 5

EDX elemental mapping images of the char residues for EP, EP/10\% 

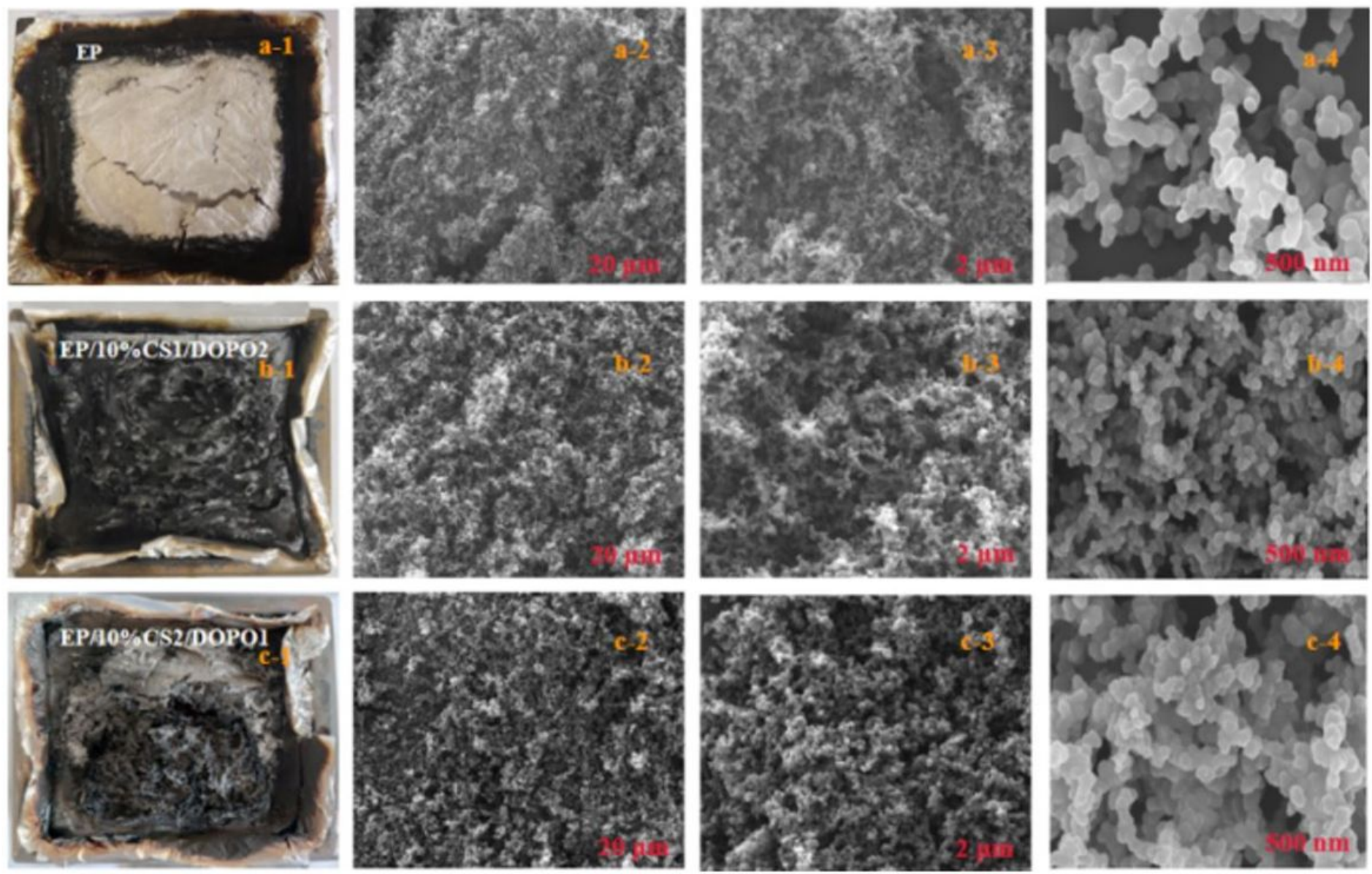

\section{Figure 6}

The digital and SEM images of the char residues from EP (a, a-1, a-2, a-3, a-4), EP/10\% CS1/DOPO2 (b, b$1, \mathrm{~b}-2, \mathrm{~b}-3, \mathrm{~b}-4)$ and EP/10\% CS2/DOPO1 (c, c-1, c-2, c-3, c-4)
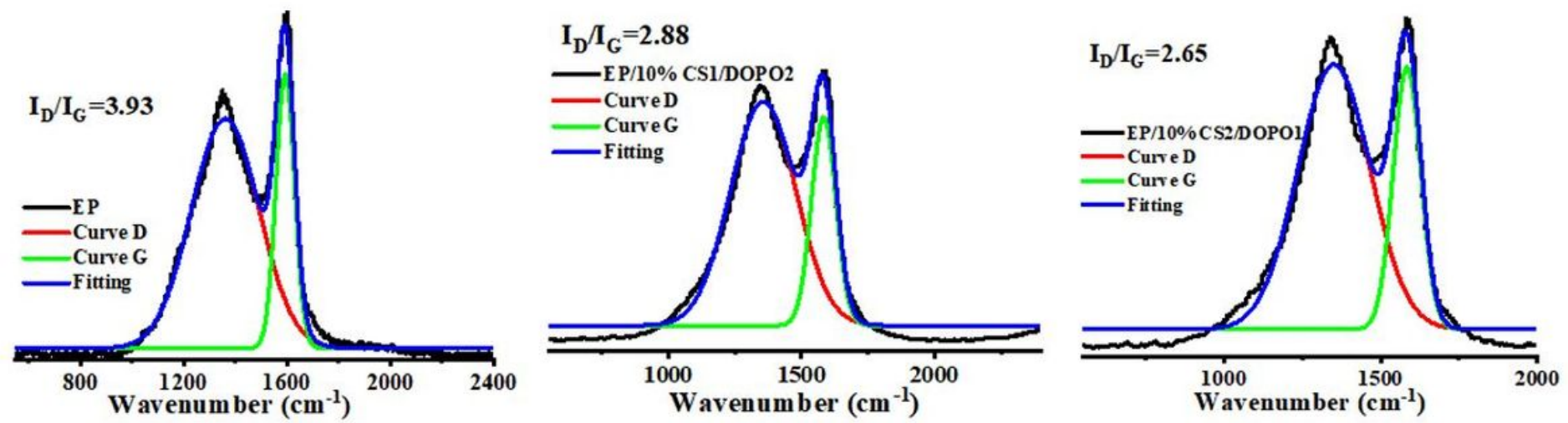

Figure 7

Raman spectra of char residues for EP, EP/10\% CS1/DOPO2 and EP/10\% CS2/DOPO1 


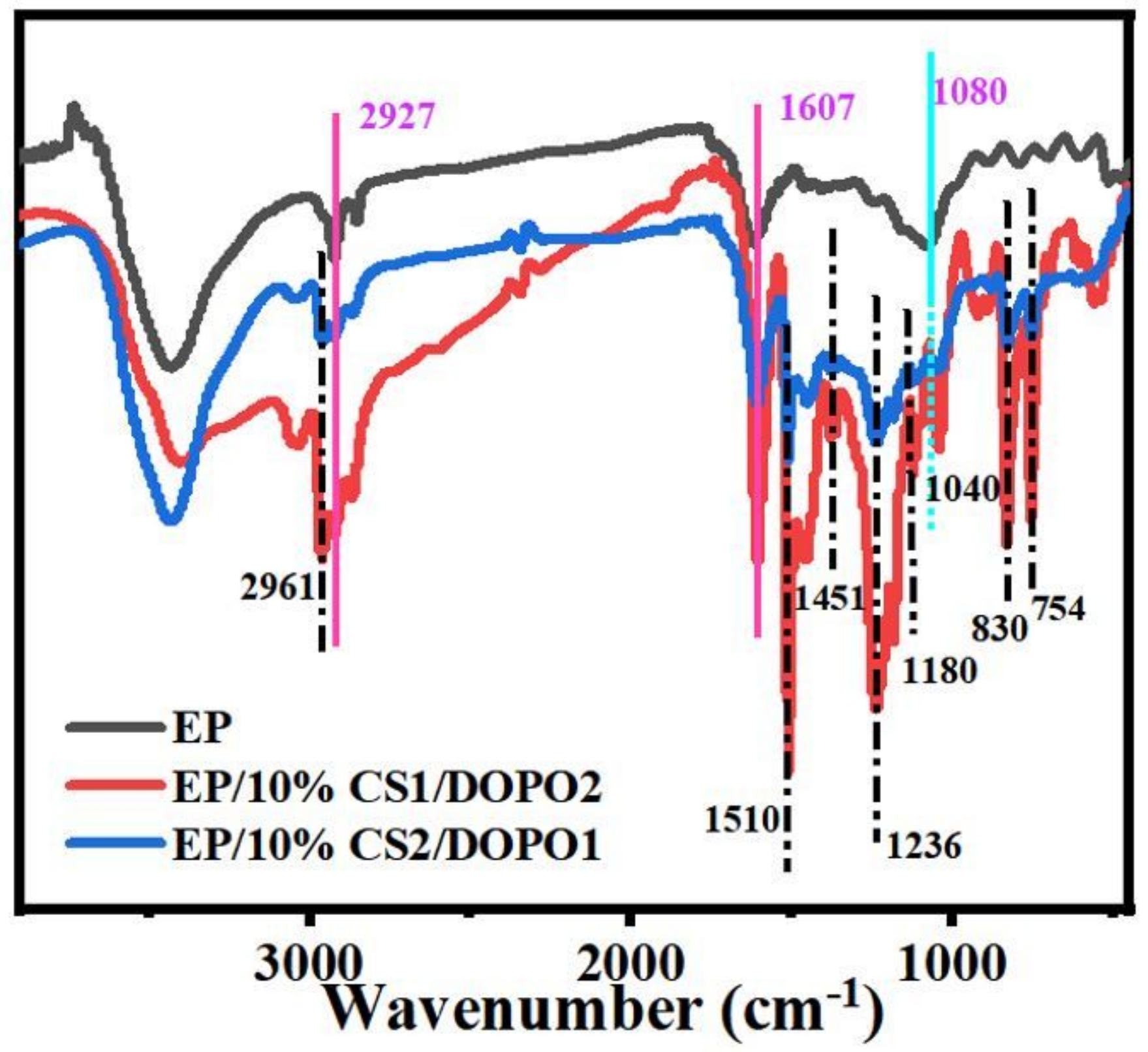

Figure 8

FTIR spectra of char residues for EP, EP/10\% CS1/DOPO2 and EP/10\% CS2/DOPO1 

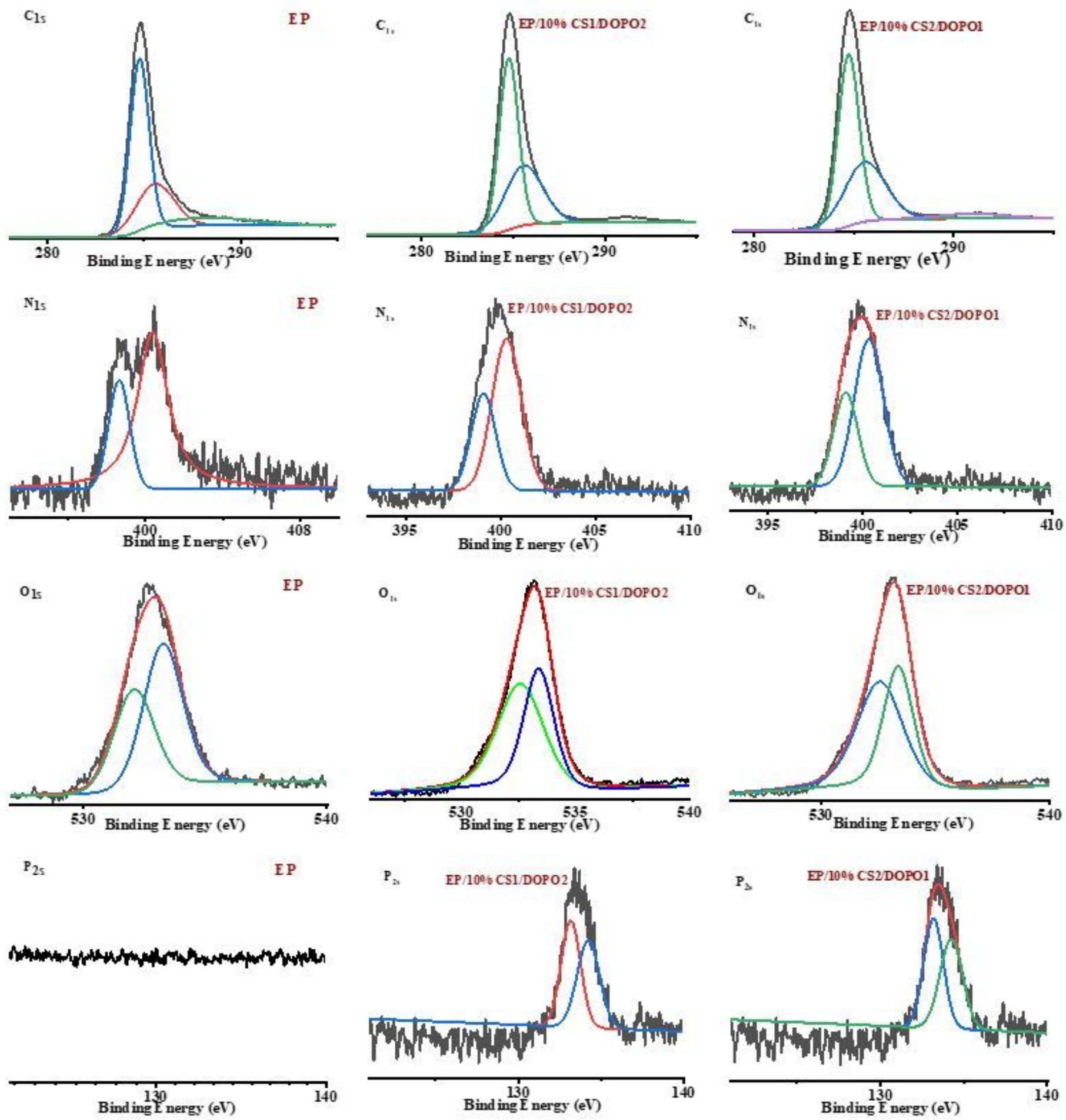

\section{Figure 9}

C1S, 01S, N1S, and P2s spectra of char residues for EP and EP/10\% CS1/DOPO2 and EP/10\% CS2/DOPO1 

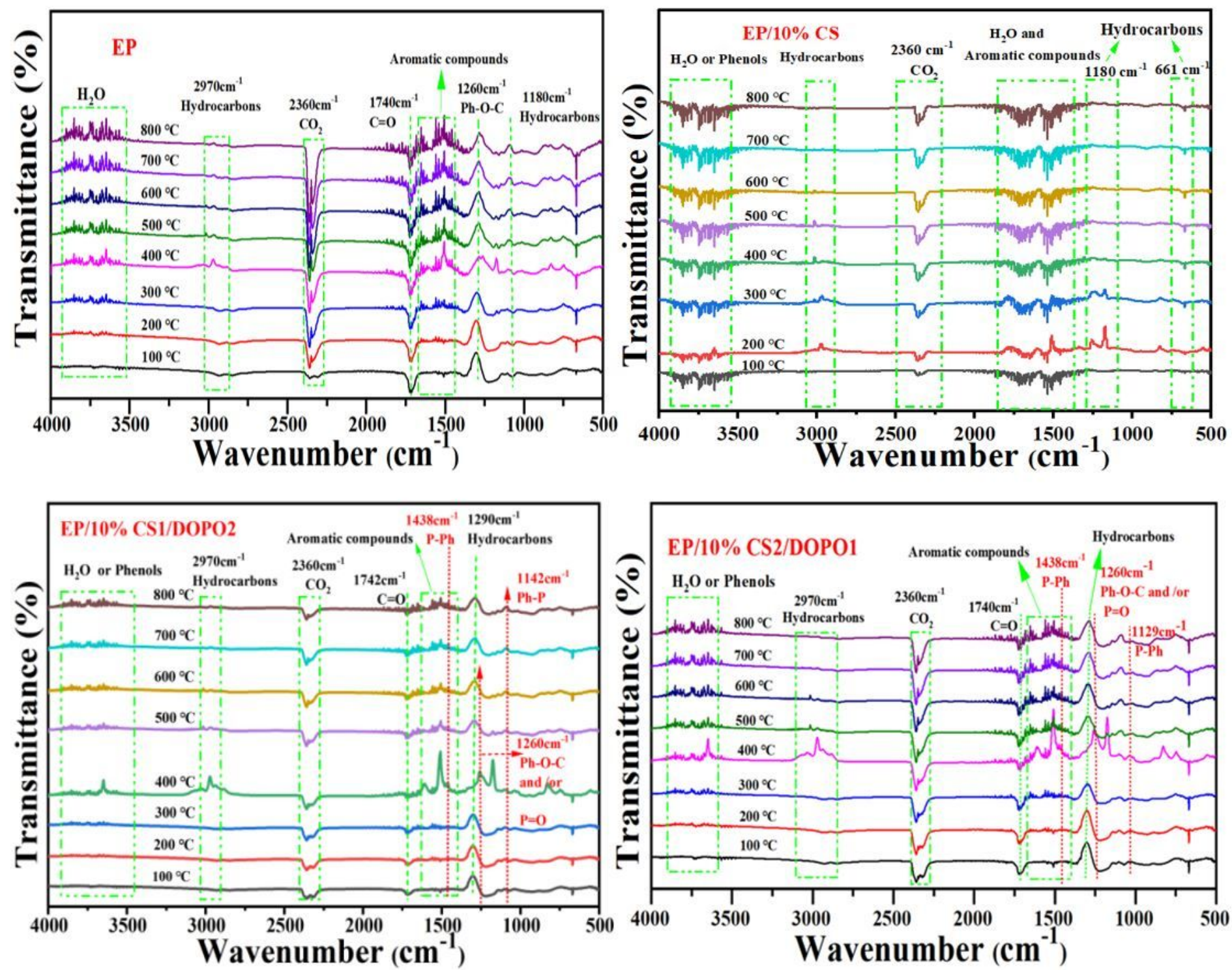

Figure 10

FTIR spectra of EP, EP/10\%CS1/DOPO2 and EP/10\% CS2/DOPO1 at various temperatures
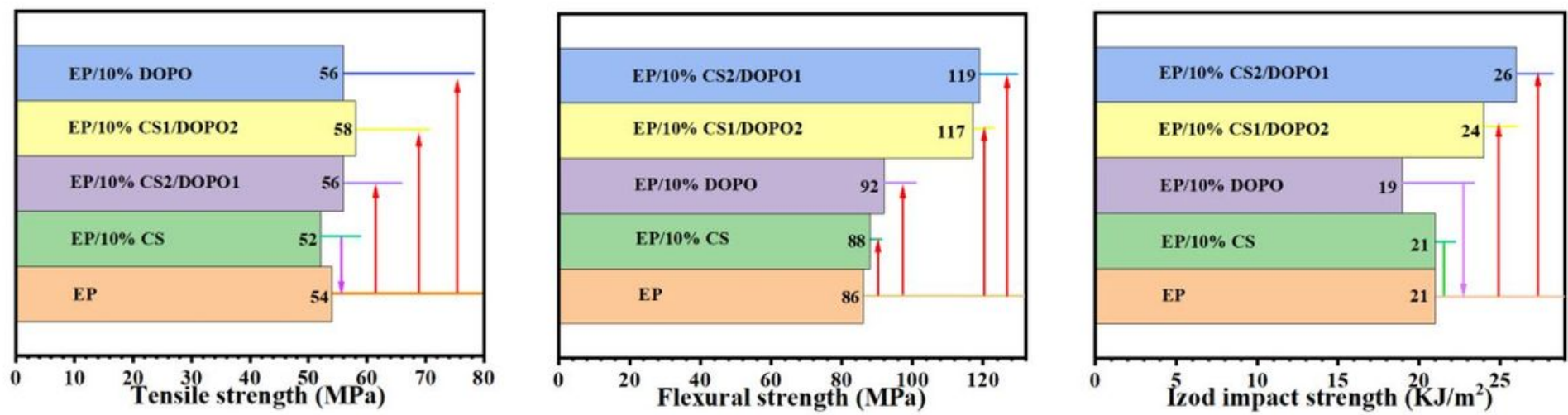

Figure 11 


\section{Supplementary Files}

This is a list of supplementary files associated with this preprint. Click to download.

- scheme1.jpg

- Graphicalabstract.docx

- SupplementaryMaterial.docx 